\title{
Mutual Penetration of Professional Education and Entrepreneurship Education in Higher Vocational Education
}

\author{
Ruochen Zhao \\ Chongqing Electric Power College, Chongqing, 3400053
}

Keywords: Higher Vocational Education, Professional Education, Entrepreneurship Education

\begin{abstract}
On the basis of expounding the present situation of innovation and entrepreneurship education in higher vocational education, this paper analyzes the existing problems and causes in the process of implementing innovation and entrepreneurship education. At the same time, it puts forward that the innovation and entrepreneurship education in higher vocational education should be integrated into the professional education system. To adjust and optimize the theoretical knowledge and practical ability to adapt to the needs of innovative and entrepreneurial talents; the implementation of innovative entrepreneurship education should be integrated into the professional education, organic integration, the development of innovative entrepreneurship, Mutual penetration; the establishment of Entrepreneurship Institute, and strengthen the conditions for innovation and entrepreneurship education.
\end{abstract}

\section{Introduction}

Professional education is the basis of entrepreneurship education, it can be said that if there is no professional education support, entrepreneurship education can not really be implemented. For higher vocational colleges, entrepreneurship education for all students is an important aspect of ensuring the quality of running a school. At present, only the positive reform of traditional education and teaching model, establish a business-oriented professional education, entrepreneurship education will be integrated in the professional education, to guide students to play a professional advantage to entrepreneurial quality and entrepreneurial ability to enhance, can really enhance the professional teaching Level, to achieve the implementation and popularization of entrepreneurship education.

At present, China's entrepreneurial education system is not perfect, to improve the quality of entrepreneurship education, we must rely on professional education. Higher vocational colleges have always attached great importance to the cultivation of students' creativity, emphasizing the innovation and reform of professional education, which already contains the basic requirements of entrepreneurial quality. Professional quality and entrepreneurial quality itself has many similarities, the integration of two kinds of education and penetration, more conducive to the improvement of the overall quality of students, contribute to the effective development of school entrepreneurship education.

Compared with the traditional teaching mode, the integration of entrepreneurship education and professional education can make the educational resources of the enterprises and enterprises be used rationally, so that students can experience the work process of the enterprise on campus, get some practical experience and master the practical skills. It can help students to solve the practical problems in professional learning, but also for knowledge applications and independent entrepreneurship has laid a good foundation for students to become the center of education and teaching, to achieve the purpose of teaching and learning combined with the meaning and significance. 


\section{The Integration of Entrepreneurship Education and Professional Education in Higher Vocational Education}

Although the overall point of view, China's higher vocational colleges have been more and more attention to entrepreneurship education, many colleges and universities also founded the students entrepreneurship park to encourage students to start, but from the relationship between entrepreneurship education and professional education is basically their own way. Many vocational colleges do not incorporate entrepreneurship education into professional education and classroom teaching. Moreover, the departments that undertake entrepreneurship education are mainly admissions and employment departments and some student management departments, rather than teaching departments, which makes entrepreneurship education and professional education open a certain distance, but also means that entrepreneurship education is still in the theoretical education and experience-based stage, and the lack of practical links.

For the development of entrepreneurship education, most of the current vocational colleges or to take the form of elective courses, the lack of reasonable arrangements for the curriculum, there is no scientific and unified teaching materials, nor the establishment of entrepreneurship education teaching and research section. In the content of entrepreneurial courses, mostly for the basic principles and methods of entrepreneurship, entrepreneurial practice is often carried out only the school unilateral, and the enterprise is relatively weak, which are difficult to cultivate the quality of students play a positive role in the training. Therefore, the higher vocational education needs professional characteristics, highlighting the practical ability, scientific, multi-level new business teaching system.

Entrepreneurship education and other courses, has a prominent practical characteristics, which entrepreneurship education level of teachers put forward higher requirements, teachers must have practical experience. Therefore, entrepreneurship education requires both solid theoretical foundation, but also need to have practical experience of teachers and entrepreneurs. At the same time, in the increasingly serious situation of employment situation, the employment consciousness has undergone a significant change, vocational students have begun to gradually out of passive employment situation, can actively seek entrepreneurial approach, there is a clear intention and demand for entrepreneurship. Therefore, in the colleges and universities to carry out entrepreneurship education, training entrepreneurship education backbone teachers and should be the current college entrepreneurship education teaching an important part.

Good entrepreneurial culture atmosphere plays an active role in guiding and shaping the students' entrepreneurial consciousness, entrepreneurial quality and innovative spirit, and also affects the initiative of vocational students to accept entrepreneurship education. At present, China's vocational colleges generally lack the environment to encourage students to start an environment and some institutions of the entrepreneurial campus culture only stay in the conservative employment campus culture, the lack of creating a culture of entrepreneurial campus awareness, but also the lack of professional practice The close contact. If the vocational colleges in the normal professional education in a reasonable, cleverly integrated into the entrepreneurial education activities of some factors, then this entrepreneurial atmosphere will be with the professional learning atmosphere gradually grow, so imperceptibly cultivate students entrepreneurial quality.

\section{Higher Vocational Technical Institute Education and Its Vocation Problems}

In the "public entrepreneurship, innovation" new situation, higher vocational education must update the educational concept, identify the target location, cultivate a certain entrepreneurial innovation ability of professional, technical skills, applied talents, with strong practical skills and practical Working ability of the workers. According to the Shanghai Institute of Educational Science, Institute of Education, Institute of Education, Institute of Higher Education, China's higher vocational education, the annual report of the survey data show that 2014 graduates of vocational graduates after six months of self-employed ratio of 3.8\%, 2011 graduate graduates After the 
proportion of independent business $2.2 \%$, compared to an increase of $72.7 \%$, showing a substantial increase in the trend.

The implementation of innovative and entrepreneurial education is not only in response to the needs of national development strategy, but also to serve the needs of social and economic development, but also the key to sustainable development of higher vocational education itself. We must believe that every higher vocational students have the potential of innovation and entrepreneurship, the whole student as the implementation of innovative entrepreneurship education, the development of the potential of vocational students, so that the future survival and development of the necessary knowledge, skills and creativity The Such as the Ningbo Health Vocational and Technical College introduced a deepening innovation and entrepreneurship education reform implementation plan, the full implementation of innovative entrepreneurship education system, reflecting the current situation of higher vocational education, new ideas and new positioning.

First of all, higher vocational education must lay a solid cultural knowledge and professional skills, knowledge and skills with a certain depth. Necessary cultural and theoretical knowledge and professional skills must have a certain forward-looking and reserves, which is the premise of sustainable development in the future. Master the solid cultural knowledge and related professional skills is both a prerequisite for employment, but also the basis for innovation and entrepreneurship, related to the follow-up development of vocational students, but also for a higher level of learning to lay a solid foundation. Second, pay attention to innovative entrepreneurs need to have a comprehensive and cross-professional knowledge and skills, knowledge and skills with a certain breadth. This requires higher vocational colleges in the professional education to cultivate complex talents, to encourage students to cross-professional selection of cross-disciplinary courses, broaden the coverage of knowledge and skills, professional education and innovative entrepreneurship education organically. With the socio-economic development, industrial transformation and upgrading, innovation and entrepreneurship require cross-disciplinary, comprehensive development is an inevitable trend. To this end, we should be the existing professional curriculum system to the comprehensive diversification of the direction of reform and optimization, to meet the training "generalist, all-talented" complex talents need.

Third, we must target students to develop innovative and entrepreneurial skills. Higher vocational education should not only tap the potential of students' innovation, awaken students' sense of innovation, but also cultivate and improve the students' entrepreneurial ability. Therefore, we should actively carry out the theoretical research and practice of innovative entrepreneurship education, summarize and draw lessons from the successful experience of innovation and entrepreneurship education Innovation and entrepreneurship education inherent law, establish and improve the innovative business education model, cultivate students 'comprehensive management and coordination ability, strengthen students' sense of innovation, learn entrepreneurial knowledge, improve innovation and entrepreneurship ability, temper and innovate the entrepreneurial will and quality.

From the position of higher vocational education and the national development strategy to the requirements of first-line technical and technical talents, the teaching content and the construction of the curriculum system should reflect the comprehensive, local, actual and advanced, so as to integrate innovative entrepreneurship education into professional education system. Comprehensive is a cross-professional courses across the post to provide students with elective, reflecting the different professional positions of mutual penetration of knowledge, the practice of mutual cross-radiation skills, to promote cross-professional cross-disciplinary teaching cooperation. Locality is the combination of professional education and local economic construction and social development, so that vocational students in the local economic development environment to accept innovation and entrepreneurship education, innovation and entrepreneurship practice, to achieve better training results. Practicality is to strengthen the practice of teaching links, pay attention to practical exercises, through school-enterprise cooperation and other means to provide practical operation of the project, so that students practice in practice drill practice practice skills, to prepare for innovation and entrepreneurship needs. Advance is to be based on the economic and social 
development trend, it is necessary to based on "today's job needs", but also consider the "tomorrow's career updates."

In the professional education should generally include the following types of courses: First, innovation and entrepreneurship knowledge courses, such as entrepreneurial knowledge, "Internet +" and other related courses should be an important teaching content of higher vocational education; second innovation and entrepreneurship courses, Such as entrepreneurial planning forum, innovation and entrepreneurship design competition, social survey, special visit, entrepreneurial success experience learning; third innovation and entrepreneurship practice courses, schools can set up innovative business funds, set up innovative business class pilot, try to social docking, set up And participate in some less investment, quick, low risk of venture projects, while the innovation and entrepreneurship activities and results by the school recognized, converted to the relevant professional courses credits. Such as Ningbo City Vocational and Technical College has begun to explore the foundation of entrepreneurship, business seminars, network entrepreneurship, innovative business thinking as a compulsory course, business law and policy, product innovation and project demonstration, innovation and entrepreneurship competition counseling, SYB and venture As a professional elective course, and give the corresponding credits.

Innovation and entrepreneurship education is individual, diversity, practical, comprehensive, is a complex system engineering, covering the education, management, economy, law, public relations, psychology, etc., in education practice, we not only We should pay attention to the system of innovation and entrepreneurship education, but also pay attention to the continuity of education and education process. We should integrate innovation and entrepreneurship education into higher vocational education system and run through the whole process of personnel training. From the school philosophy, personnel training programs, teaching methods, practice training, student management, teacher building and related rules and regulations, and so on through innovation and entrepreneurship education this line, focus on improving and cultivating vocational students innovation and entrepreneurship awareness, quality, knowledge And skills. Higher vocational colleges themselves must emancipate their minds, keep up with the development trend of the times, and strive to reform and innovation in higher vocational education. For example, many higher vocational colleges in our province have set up a business college to consider the implementation of innovation and entrepreneurship education.

\section{Conclusion}

Professional education and entrepreneurship education integration set of knowledge education and quality education in one, reflecting the future development of higher vocational education trend. This new concept of entrepreneurial education has changed the traditional entrepreneurial education thought, not only to enhance the quality of personnel training content for the development of vocational education to establish an accurate positioning, but also broaden the employment of vocational students entrepreneurial approach to ease the community Employment pressure, for students themselves, vocational colleges and social stability and development have a very important practical significance. As an educator, we must grasp the training objectives of higher vocational education, and constantly improve the understanding of entrepreneurship education and professional education for the integration of entrepreneurship education and professional education to actively explore more effective way.

\section{References}

[1] Zhao Yuesong. The higher vocational education machinery professional practice teaching [J]. Economic and trade practice, 2017 (02)

[2] Zeng Jianlan. Chinese higher vocational education reform based on the concept of Australian vocational education [J]. Modern communication, 2017 (01)

[3] Yang Zhigang, Su Qiaorong. Problems and Countermeasures of Students in Higher Vocational 
Colleges [J]. Journal of Yellow River Conservancy Technical Institute, 2017 (02)

[4] Zhang Bin, Chen Siyan. The development of higher vocational education problems and countermeasures [J]. Wuxi Nanyang Vocational and Technical College, 2016 (Z1)

[5] Li Yueshun, Wang Cuili. Study on the Development Strategy of Shaanxi Higher Vocational Education [J]. Journal of Shaanxi Vocational and Technical College, 2004 (08) 